

\title{
The Optimum Structure for Government Debtt1
}

\author{
Wolfgang Kuhle ${ }^{a, b}$ \\ ${ }^{a}$ MEA Mannheim, L13, 17, 68131 Mannheim Germany, \\ wkuhle@mea.uni-mannheim.de,0049-(0)621-1811858 \\ ${ }^{b}$ Department of Economics, Mannheim University
}

\section{First Version December 2007}

\section{This Version February 2009}

\begin{abstract}
This article studies the structural differences between implicit and explicit government debt in a two-generations-overlapping model with stochastic factorprices. If a government can issue safe bonds and new claims to wage-indexed social security to service a given initial obligation, there exists a set of Pareto-efficient ways to do so. This set is characterized by the conflicting interests of the current young and the yet unborn generations regarding the allocation of factor-price risks. However, it is shown that there will always exist a simple intertemporal compensation mechanism which allows to reconcile these conflicting interests. This compensation mechanism narrows the set of Pareto-efficient debt structures until only one remains. This result hinges on the double-incomplete markets structure of stochastic OLG models where households can neither trade consumption-loans nor factor-price risks privately.
\end{abstract}

Keywords: Public debt, Implicit, Explicit, (ex-ante) Pareto-efficiency, Risk-sharing. JEL: H55

\footnotetext{
${ }^{1}$ I would like to thank my advisors Axel Börsch-Supan and Alexander Ludwig for their support and helpful comments. I would also like to thank Nataliya Demchenko, Klaus Jaeger, Martin Salm and Edgar Vogel for helpful discussion. This research was carried-out at Mannheim University from November 2007 to February 2009. Financial support from the German Research Foundation, the German Insurers Association and the state Baden-Württemberg is gratefully acknowledged. All remaining errors are mine.
} 


\section{Introduction}

Privatizing social security has often been described as a pure "shell game", where an implicit liability is replaced by an explicit liability of equal size. ${ }^{2}$ This equivalence between implicit and explicit government debt has often been described as a counterpart to the Modigliani-Miller Theorem in corporate finance. The underlying argument for this irrelevance result has its roots in the consumption-loan nature of both debt instruments. A pure reallocation of resources between two adjacent cohorts can at most yield the biological interest rate ${ }^{3}$ For a deterministic economy, which is dynamically efficient in the sense of Diamond (1965), bonds are issued with a rate of return that is, at first sight, superior to the biological return earned on social security contributions. However, to prevent an eventual default, the government has to collect a tax that exactly offsets this return advantage. Taking these taxes into account, both instruments yield identical allocations 4 In particular, they reduce long-run utility by crowding out capital.

In stochastic overlapping generations models Enders and Lapan (1982), Merton (1983), Gordon and Varian (1988), Gale (1990), Krüger and Kubler (2005) and Gottardi and Kubler (2008) have shown that, intergenerational transfers via PAYGO pension schemes and safe government debt may serve a second role as they allow to facilitate intergenerational risk-sharing. ${ }^{5}$ In-turn, these beneficial aspects of government debt have been compared to the negative long-run losses which stem from the crowding out of capital. In particular Green (1977), Krüger and Kubler (2005)

\footnotetext{
${ }^{2}$ See e.g. Breyer (1989), Fenge (1995), Belan and Pestieau (1999), Friedman (1999). See Sinn (2000) for a survey. Samuelson (1975) proves the related result that fully funded social security is also neutral. More recently, Ludwig and Reiter (2009) have extended the result to a stochastic setting with state dependent taxes.

3 Samuelson (1958, 1959), Lerner (1959), Aaron (1966) and Cass and Yaari (1966). In the sequel, we abstract from technological progress as it does not change the basic tradeoffs.

${ }^{4}$ Both schemes pay the same returns, cause (in absence of intragenerational redistribution) the same excess burdens in the labor market, reallocate the same amount of resources between generations, displace an equal amount of private savings and lower long-run utility.

${ }^{5}$ In particular, Fischer (1983) and Gale (1990), discuss the desirability of safe debt and its maturity structure in an OLG context with rate-of-return risk. Enders and Lapan (1982) examine a mature pay-go scheme in an economy where fiat money is the only alternative store of value. Merton (1983) derives closed from solutions for a three period OLG model with simultaneous demographic, TFP and income share risks. He shows that a tax and transfer system may replicate an (incomplete markets) equilibrium where agents can trade human capital freely. In the Merton (1983) setting such an intervention is always warranted as young agents would starve under "total market failure". Bohn (1998, 2003) shows that a constant debt to GDP ratio leads to pro-cyclical debt issues, that amplify aggregate risks. Starting from a situation without government debt, Krüger and Kubler (2005) give numerical evidence that the introduction of unfunded social security is unlikely Paretoimproving - despite its risk sharing capacities - due to the crowding out of capital. Gottardi and Kubler (2008) discuss the prospects of an ex-ante Pareto-improving introduction of unfunded social security in an economy with land. See Diamond (1977, 2000) for a broader assessment of intergenerational and intragenerational insurance aspects of social security, and Shiller (1999) for more references on the sharing of aggregate risks. See Abel (2001), Diamond and Geanakoplos (2003), and Ball and Mankiw (2007) for different approaches to utilize trust-fund assets - a question somewhat related to the present one. To focus firmly on the unfunded component of social security we will not introduce a trust-fund.
} 
and Gottardi and Kubler (2008) have analyzed this trade-off between risk-sharing and worsening factor-prices. Their analysis indicates that even the introduction of a very small social security system decreases long-run utility. That is, the positive risk-sharing effect is dominated by the negative crowding-out effect.

The current paper complements this literature in the following sense: it is shown that it is possible to implement the diversification of labor-income risk purely by a change in the composition of the existing debt. These changes in the composition of the public debt leave the expected intergenerational transfer constant over time but alter the allocation of income risks. That is, instead of asking whether new debt should be issued to facilitate intergenerational risk sharing, we ask whether it is possible to restructure the existing debt in a Pareto-improving manner. We approach this question in a setting where each member of an initial old generation holds claims from past pension promises and debt issues amounting to $g_{0}$. The government can now raise a share $\lambda$ of the needed revenue through the introduction of a linear social security tax on the current young generations wage income. The remainder share $1-\lambda$ will then be raised by selling safe debt. Finally, the group of yet unborn generations will in-turn have to service future pension claims issued to the current young generation.

The main results obtained in this setting are, (i) if the government can only change the composition of the existing debt, there will be a set of efficient debt structures and another set of inefficient ones. The efficient set is characterized by the conflicting interests of those agents who are currently young and those who are yet unborn. The unborn generations benefit from the ex-ante diversification of their wage risk if a large share $\lambda$ of the initial debt is injected into social security. The current young, who have already observed their wage income, will on the contrary prefer safe debt, i.e. safe retirement benefits; (ii) if the government can also issue/recover additional bonds, i.e. change the size of the expected future intergenerational transfers, the set described in (i) can be narrowed to only one Pareto-optimal debt structure, which maximizes societies "marshallian surplus" from intergenerational risk sharing.

This second result appears to be of particular interest, when compared to the problem of optimal capital accumulation in a deterministic Diamond (1965) model. In analogy to our result (i), there always exists an efficient set of capital intensities. This means every change in the capital intensity requires a welfare criterion as we can either shift resources into the future or redirect resources from the future towards current generations ${ }^{6}$ In the present stochastic setting, however, we show that it is possible to compensate intertemporally. We can shift resources and risks between the current young and the yet unborn members of society simultaneously and independently. As a consequence, the government can narrow the set of efficient debt structures until only a single efficient structure remains.

Regarding our assumptions, a notable aspect of our analysis is that we rule-

\footnotetext{
${ }^{6}$ The lack of such a compensation mechanism led to the turnpike literature, see, e.g., Samuelson (1968) or Blanchard and Fischer (1989). The absence of such an intertemporal compensation mechanism is of course also the reason for the intertemporal efficiency of pay-go schemes that we have been referring to in footnote 1 .
} 
out state-contingent lump-sum transfers. Following Merton (1983), Gordon and Varian (1988), Bohn (1998, 2003), Krüger and Kubler (2005) and Gottardi and Kubler (2008) we try to capture the basic features of most real-world pension and debt schemes by limiting the government debt instruments to safe bonds and a linear social security contribution rate on wages. While state-contingent lump-sum transfers may allow to reach better allocations than our simplistic debt instruments, they are not observed in actual policy. Secondly, the optimal allocations which are derived for such state-contingent tax and transfer systems usually imply that the public debt follows a random walk as described in Gordon and Varian (1988) and Ball and Mankiw (2001, 2007).7 Hence, if the government would actually implement these policies, it would default in finite time with probability one. One may therefore argue that such a risk-sharing policy amplifies rather than dampens the small risks faced by each generation as they create a tremendous default risk.

Subsequently, we begin in Section 2 by laying out our model. Regarding the representative households, we assume that they maximize expected utility. Moreover, first and second period consumption are assumed to be normal goods. Savings can be invested in a risky and a safe production technology. Wages are determined according to a third risky technology. As in Diamond and Geanakoplos (2003), it is assumed that aggregate investment does not affect marginal returns. This tri-linear setting will help us to bring out the underlying economic mechanisms more clearly 8 In a different interpretation we may think of our model as a small open economy. Subsequently, we introduce the budget constraints of the social security system and the treasury. With these assumptions in place, we derive our two main results $(i)$ and (ii) in Section 2. In Section 3, we show that our results carry over once some of our restrictive assumptions made in Section 3 are relaxed. In particular, the assumption of a constant risk-free rate will be dropped. Moreover, we consider a defined benefit social security system, and an economy with intra-cohort heterogeneity. Section 4 offers concluding remarks.

\section{The Model}

\subsection{Population and Factor Prices}

The economy is inhabited by two-period-lived agents that form overlapping generations. During the first period of life each agent supplies one unit of labor inelastically.

\footnotetext{
7 Gordon and Varian (1988), p. 192, and Ball and Mankiw 2001, 2007) (Proposition 2), point out that their debt schemes that reallocate risks "optimally" imply that per capita debt will follow a random walk. Hence per-capita debt will hit any boundary in finite time. Consequently, as Gordon and Varian (1988), p. 192 point out, the economies total assets will eventually be negative, forcing the government to default at some point.

${ }^{8}$ As the per capita size of expected intergenerational transfers will be kept constant over time we do not expect large changes in aggregate savings once implicit debt is replaced by explicit debt (cf. Diamond (1996)). Hence the crowding-out effects along the neoclassical competitive factorprice-frontier, which are so notable when additional debt is issued, do not come into play in the current analysis.
} 
Population evolves according to:

$$
N_{t+1}=(1+n) N_{t}
$$

where $N_{t}$ is the size of the cohort born in period $t$ and $1+n$ is the number of children raised by each member of cohort $t$.

The wage rate $w_{t}$ and the interest rate to risky capital $R_{t}$ are both stochastic. They follow an exogenously given, serially i.i.d., distribution. The stochastic wage rate $w_{t}$ realized in period $t$ has a lower bound $\check{w}>0$. Risky investments have the limited liability property, i.e. $\check{R}_{t} \geqq-1$. Furthermore the rate of return $R_{t}$ may be correlated with the wage rate $w_{t}$, i.e. $\operatorname{cov}\left(w_{t}, R_{t}\right) \gtreqless 0$. In our baseline specification we assume that the safe rate $r$ is exogenously given; respectively defined by a safe linear technology. In the sequel we also assume that $\check{R}<r<E[R]$, such that both risky and riskfree assets may be held by risk-avers investors. In Section 3, we relax the assumption of a constant riskfree rate.

\subsection{Implicit and Explicit Government Debt}

The government can interact with the competitive economy both via an unfunded pay-as-you-go social security system and through the intertemporal budget constraint of the treasury. While both of these schemes may be used to roll over debt, they differ with respect to the way that wage-income is taxed.

An unfunded social security system with a contribution rate $\tau^{s}$ and per capita benefits $p$ is characterized by its budget constraint:

$$
\tau_{t}^{s} w_{t} N_{t}=p_{t} N_{t-1}
$$

Using the biological interest rate relation (11), constraint (2) can be rewritten, such that per capita pension benefits are given by:

$$
p_{t}=(1+n) \tau_{t}^{s} w_{t}
$$

Equation (3) indicates that an agent born in period $t$ will contribute an amount $\tau^{s} w_{t}$ to the pension system in exchange for uncertain future benefits $(1+n) \tau_{t}^{s} w_{t+1}$. In terms of expectations, the consumption loan scheme will grow at rate $n$ if the contribution rate is fixed. In this case, it remains constant in per capita terms:

$$
E_{w_{t+1}}\left[p_{t+1}\right]=(1+n) \tau^{s} E_{w_{t+1}}\left[w_{t+1}\right]
$$

The second channel through which the government can roll over debt is the treasury's budget constraint. Denoting the total amount of outstanding debt by $B_{t-1}$, the amount of newly issued debt by $B_{t}$ and the treasury's tax rate by $\tau_{t}^{t}$, the treasury's intertemporal budget constraint for period $t$ is:

$$
B_{t}=\left(1+r_{t}\right)\left(B_{t-1}-N_{t-1} \tau_{t-1}^{t} w_{t-1}\right) .
$$

Defining per capita debt $b_{t} \equiv \frac{B_{t}}{N_{t}}$ and substituting (1), into (5) yields:

$$
(1+n) b_{t}=\left(1+r_{t}\right)\left(b_{t-1}-\tau_{t-1}^{t} w_{t-1}\right)
$$


If no taxes were levied, per capita debt would grow at a proportional rate of $\frac{r_{t}-n}{\left(1+r_{t}\right)}$, from period $t-1$ to period $t$. To ensure that in per capita terms no additional debt is passed forward from generation $t-1$ to generation $t$, the treasury has to collect taxes from generation $t-1$ amounting to:

$$
\tau_{t-1}^{t} w_{t-1}=\frac{r_{t}-n}{\left(1+r_{t}\right)} b_{t-1}
$$

Taxes are either positive or negative depending on whether the returns to intergenerational redistribution dominate market returns, i.e. if $r \gtreqless n 9^{9}$

\subsection{The Structure of Government Debt}

At the beginning of time there is an initial generation -1 of retirees and a generation 0 of workers. The generation of retirees holds per capita claims to an existing social security system and/or from past issues of government debt, amounting to $g_{0}$. To service these claims the government has to raise a revenue of $\frac{g_{0}}{1+n}$ from each member of generation 0 . A share $\lambda \in[0,1]$ of the needed revenue can now be raised via the initiation of an unfunded pay-go scheme with a defined contribution rate $\tau^{s}: 10$

$$
\tau_{0}^{s} w_{0} N_{0}=\lambda g_{0} N_{-1}, \quad \Leftrightarrow \quad \tau^{s}=\tau_{0}^{s}=\frac{\lambda}{w_{0}} \frac{g_{0}}{(1+n)} .
$$

The remainder share $(1-\lambda)$ can then be raised by issuing safe government bonds:

$$
(1-\lambda) g_{0} N_{-1}=B_{0}, \quad \Leftrightarrow \quad(1-\lambda) \frac{g_{0}}{(1+n)}=b_{0}
$$

Recalling (7), per capita taxes in period 0 must satisfy:

$$
\tau_{0}^{t}=(1-\lambda) \frac{\left(r_{1}-n\right)}{\left(1+r_{1}\right) w_{0}} \frac{g_{0}}{(1+n)} .
$$

Once we do not ask any future generation to redeem the debt, all subsequent generations will be taxed according to:

$$
\tau_{t}^{t}=(1-\lambda) \frac{r_{t+1}-n}{\left(1+r_{t+1}\right) w_{t}} \frac{g_{0}}{(1+n)}
$$

Inspection of (8) and (11) immediately yields the equivalence proposition that we have been referring to in the introduction.11

\footnotetext{
${ }^{9}$ The taxes needed to keep per capita debt from growing to infinity, will be paid by the young consumers. However, as long as the representative agent invests into the riskfree technology, he will be indifferent between a tax of $\frac{\left(r_{t+1}-n\right) g_{0}}{\left(1+r_{t+1}\right)(1+n)}$ when young or a tax of $\frac{\left(r_{t+1}-n\right) g_{0}}{(1+n)}$ when old.

${ }^{10}$ Note that as with the explicit debt scheme, the amount resources transferred via social security may not permanently outpace the economy. At the same time lowering the contribution rate would amount to a repayment of some debt by the affected generation of retirees. To make both schemes feasible and comparable, we therefore fix $\tau^{s}$.

${ }^{11}$ In the standard Diamond (1965) economy, the steady state budget constraint of the representative agent reads $c^{1}+\frac{c^{2}}{1+r}=w\left(1-\tau^{s}-\tau^{t}\right)+\frac{\tau^{s} w}{1+r}(1+n)$. Plugging the two budget constraints of the treasury (11) and the social security administration (8) into this budget constraint yields for the right-hand-side: $w-\frac{r-n}{1+r} \frac{g_{0}}{1+n}(1-\lambda)-\frac{g_{0}}{(1+n)} \lambda+\lambda \frac{g_{0}}{1+r}=w-\frac{(r-n) g_{0}}{(1+r)(1+n)}$. The life-cycle savings condition is also independent of $\lambda:(1+n)\left(\lambda \frac{g_{0}}{1+n}+(1-\lambda) \frac{g_{0}}{1+n}+k\right)=g_{0}+(1+n) k=s$. Hence the structure of debt is irrelevant as it neither affects the household's budget constraint nor the life-cycle savings condition.
} 


\subsection{The Optimum Structure for Government Debt}

In this section we will start by tracing out the interests of the current young regarding the structure for government debt $\lambda$. Subsequently, we will characterize the interests of the yet unborn generations. With these results at hand we will derive our two main results in Section 2.5. A representative member of cohort 0 can allocate his net income to first period consumption $c^{1}$, invest an amount $a_{0}$ into the safe technology and devote $h_{0}$ to the risky technology:

$$
\begin{array}{rlrl}
\max _{c^{1}, c^{2}} & W & =U\left(c^{1}\right)+\beta E_{w R}\left[U\left(c^{2}\right)\right] ; \quad U^{\prime}()>0, \quad U^{\prime \prime}()<0, \\
\text { s.t. } & c^{1}=w_{0}\left(1-\tau_{0}^{t}-\tau_{0}^{s}\right)-a_{0}-h_{0}, \\
c^{2}=a_{0}(1+r)+h_{0}\left(1+R_{1}\right)+\tau_{0}^{s} w_{1}(1+n) .
\end{array}
$$

The corresponding first order conditions, which imply $a_{0}^{*}$ and $h_{0}^{*}$, are:

$$
\begin{aligned}
& \frac{\partial W}{\partial a_{0}}=-U^{\prime}\left(c^{1}\right)+\beta(1+r) E_{w R}\left[U^{\prime}\left(c^{2}\right)\right]=0, \\
& \frac{\partial W}{\partial h_{0}}=-U^{\prime}\left(c^{1}\right)+\beta E_{w R}\left[(1+R) U^{\prime}\left(c^{2}\right)\right]=0 .
\end{aligned}
$$

If felicity, $U()$ in (12), is such that first and second period consumption are normal goods we have ${ }^{12}$

$$
s=s\left(w_{t} ; \tau^{s}\right) \equiv a+h ; \quad 0<\frac{\partial s}{\partial w_{t}}<\left(1-\tau^{s}\right) .
$$

Equipped with these conditions, the social planner can, disregarding the utility of subsequent generations for the moment, use the two debt instruments by choosing $\lambda$ such that the indirect utility of generation 0 is maximized. Taking into account the budget constraints (8) and (10) yields the planning problem: ${ }^{13}$

$$
\begin{aligned}
\max _{\lambda} V_{0}=\quad & U\left(w_{0}\left(1-\tau_{0}^{s}-\tau_{0}^{t}\right)-a_{0}-h_{0}\right) \\
& +\beta E_{w R}\left[U\left(a_{0}(1+r)+h_{0}(1+R)+\tau_{0}^{s} w(1+n)\right)\right],
\end{aligned}
$$

$$
\text { s.t. (8), 10. }
$$

Utilizing the envelope condition $(13)$ and the covariance rule, $\lambda^{*}$ is implicitly defined by:

$$
\frac{d V_{0}}{d \lambda}=\frac{U^{\prime}\left(c^{1}\right) g_{0}}{1+r}\left(\frac{E[w]-w_{0}}{w_{0}}+\frac{\operatorname{cov}_{w R}\left(U^{\prime}\left(c^{2}\right), w_{1}\right)}{w_{0} E_{w R}\left[U^{\prime}\left(c^{2}\right)\right]}\right)=0
$$

\footnotetext{
${ }^{12}$ The increment in income from a high realization of $w_{t}$ is given by $\left(1-\tau^{s}-\tau^{t}\left(w_{t}\right)\right)+\frac{\partial \tau^{t}\left(w_{t}\right)}{\partial w_{t}} w_{t}=$ $\left(1-\tau^{s}\right)$.

${ }^{13}$ Note that there is no life-cycle savings condition for bonds and capital in a small open economy, i.e. we only take note of the taxes that are needed to keep per capita debt from growing. In a closed economy with a tri-linear technology, we can also neglect the market clearing condition as long as agents demand safe investments in excess of the debt offered. In the following we assume that agents are equating at the margin, i.e. we omit the prospect of Kuhn-Tucker-type ramifications.
} 
Condition (17), which is reminiscent of the C-CAPM, indicates that members of generation 0 will benefit from a high fraction of debt that is injected into the social security system as long as the expected excess rate-of-return on this fraction of debt, compared to the after-tax-return on safe bonds, is positive, i.e. $\frac{E w-w_{0}}{w_{0}}>0$. The other relevant component is the covariance between second period marginal utility and the pension benefit. Depending on $\operatorname{cov}\left(R_{1}, w_{1}\right) \gtreqless 0$, we have $\operatorname{cov}\left(U^{\prime}\left(c^{2}\right), w_{1}\right)_{\mid \lambda=0} \lesseqgtr 0$, i.e. the wage-indexed social security claims may or may not be a welcome opportunity to diversify stock market risks.

\subsubsection{Subsequent Generations}

The social planner's perspective on the welfare of subsequent generations, which is obviously connected to the current choice of $\lambda$, will be an ex-ante perspective. While the social planner knows the distribution over $R$ and $w$, the realizations are yet unknown. The agents, however, will start to make their consumption savings decisions after $w_{t}$ has been realized. The consumers' behavior is therefore still characterized by conditions (13) and (14) which imply the wage dependent investment decisions $a_{t}=a_{t}\left(w_{t} ; \lambda\right)$ and $h_{t}=h_{t}\left(w_{t} ; \lambda\right)$. Put differently, the social planner, who optimizes ex-ante utility, has to take note of the agents' investment decisions conditional on the realization of $w_{t}$. Moreover, the budget constraints (8) and (11) have to be satisfied in each period. From the perspective of period 0, the planning problem is therefore given by:

$$
\begin{array}{cl}
\max _{\lambda} \quad V_{t}=\quad & E_{w_{t}}\left[U\left(w_{t}\left(1-\lambda \frac{g_{0}}{w_{0}(1+n)}\right)-\frac{r-n}{(1+r)} \frac{(1-\lambda) g_{0}}{(1+n)}-a_{t}-h_{t}\right)\right](18) \\
& +\beta E_{w_{t} w_{t+1} R_{t+1}}\left[U\left(a_{t}(1+r)+h_{t}(1+R)+\lambda \frac{g_{0}}{w_{0}} w_{t+1}\right)\right] .
\end{array}
$$

The first order condition for an optimum debt structure, taking the envelope conditions (13) and (14) into account (see Appendix A), is then given by ${ }^{14}$

$$
\begin{aligned}
\frac{d V_{t}}{d \lambda}= & \frac{g_{0}}{(1+n)}\left(\frac{n-r}{1+r} \frac{E[w]-w_{0}}{w_{0}} E_{w_{t}}\left[U^{\prime}\left(c^{1}\right)\right]\right. \\
& \left.-\operatorname{cov}_{w_{t}}\left(U^{\prime}\left(c^{1}\right), \frac{w_{t}}{w_{0}}\right)+\beta(1+n) \operatorname{cov}_{w_{t} w_{t+1} R}\left(U^{\prime}\left(c^{2}\right), \frac{w_{t+1}}{w_{0}}\right)\right)=0 .
\end{aligned}
$$

Equation (19) characterizes the debt structure $\lambda^{* *}$ which maximizes long-run expected utility. Inspection of (19) indicates that agents who are not yet born will suffer a loss from excessive intergenerational redistribution if the safe returns exceed the biological returns on consumption loans. That is the expected excess amount of resources - when compared to bonds which are not wage-indexed - that is

\footnotetext{
${ }^{14}$ Taking advantage of our assumption that the stochastic wage rate $w_{t}$ is serially uncorrelated we may rewrite $\operatorname{cov}_{w_{t} w_{t+1} R}\left(U^{\prime}\left(c^{2}\right), \frac{w_{t+1}}{w_{0}}\right)=\operatorname{cov}_{w_{t+1} R}\left(E_{w_{t}} U^{\prime}\left(c^{2}\right), \frac{w_{t+1}}{w_{0}}\right)$. If such a serial correlation existed, it would affect the location of $\lambda^{* *}$. If $a$ and $h$ are normal, we have $\frac{d a}{d w_{t}}>0$ and $\frac{d h}{d w_{t}}>0$; thus we would have a smaller $\lambda^{* *}$ if $\operatorname{cov}\left(w_{t}, w_{t+1}\right)>0$, and vice versa.
} 
redistributed via social security is given by $\frac{E w-w_{0}}{w_{0}} 15$ The second element is the intergenerational diversification of wage-income risk. With $\lambda>0$ we have a positive social security tax rate $\tau^{s}$ which transfers some of the risk associated with the realization of $w_{t}$ into period $t+1$, where $w_{t+1}$, i.e. the pension benefits are realized. The sufficient condition for an interior optimum requires that $\frac{d V}{d \lambda}$ is downward-sloping in $\lambda$. A first inspection of 19 suggests $\frac{d \operatorname{cov}\left(U^{\prime}\left(c^{1}\right), w_{t}\right)}{d \lambda}>0, \frac{d \operatorname{cov}\left(U^{\prime}\left(c^{2}\right), w_{t+1}\right)}{d \lambda}<0$, and therefore $\frac{d^{2} V}{d \lambda^{2}}<0$. Hence, as we shift wage-income risk from the first into the second period, we expect the wage related covariance risk to move in the same direction (see Appendix B for the associated conditions). However, as the set of admissible debt structures is closed and bounded, there will always exist a "best" debt structure $\lambda^{* *} \in[0,1]$.

The efficiency of the size of the debt scheme can be assessed once we ask whether the unborn generations benefit from a larger initial debt. Taking the first derivative of $V_{t}$ with respect to $g_{0}$ yields:

$$
\begin{aligned}
{\frac{d V_{t}}{d g_{0} \mid d \lambda=0}}= & \frac{n-r}{(1+r)(1+n)}\left(\frac{w_{0}+\lambda\left(E[w]-w_{0}\right)}{w_{0}}\right) E\left[U^{\prime}\left(c^{1}\right)\right] \\
& +\lambda \frac{1}{(1+n)}\left((1+n) \beta \operatorname{cov}\left(E_{w_{t}}\left[U^{\prime}\left(c^{2}\right)\right], \frac{w_{t+1}}{w_{0}}\right)-\operatorname{cov}\left(U^{\prime}\left(c^{1}\right), \frac{w_{t}}{w_{0}}\right)\right) \gtreqless 0 .
\end{aligned}
$$

The first element in 20 is the familiar return condition; larger intergenerational reallocation of resources is desirable as long as consumption-loans dominate market returns. The second element reflects the benefits from intergenerational risk-sharing through the share $\lambda$ of debt that is injected into the pension system. To see this more clearly, we recall (19) and rearrange 20 such that:

$$
{\frac{d V_{t}}{d g_{0}}}_{\mid d \lambda=0}=\frac{n-r}{(1+r)(1+n)} E\left[U^{\prime}\left(c^{1}\right)\right]+\frac{\lambda}{g_{0}} \frac{d V_{t}}{d \lambda} \gtreqless 0 .
$$

If $\lambda$ is zero or at its long-run optimum $\lambda^{* *}$, the second, risk-sharing related term vanishes and (21) exhibits the pure interest condition.

Furthermore, (21) indicates that safe debt does not reallocate any risks, while social security does. This is the opposite of the Bohn $(1998,2003)$ conclusion, where debt was issued pro-cyclical such that it shifted risks towards future generations. Equation (21) also shows that if the national debt is small, then this debt should be injected entirely into the pension scheme if $\frac{d V_{t}}{d \lambda}, \frac{d V_{0}}{d \lambda}>0$, such that the benefits from risk-sharing are maximized with $\lambda=1$. In a different interpretation, the sign of (21) is the subject studied by Green (1977), Krüger and Kubler (2005), Gottardi and Kubler (2008).

\footnotetext{
${ }^{15}$ The expected intergenerational transfer through social security is $E\left[\tau^{s} w\right]=\frac{g_{0}}{(1+n) w_{0}} E w$. Regarding bonds, the transfer is $\frac{g_{0}}{(1+n)}$. The difference in the expected size of the transfers, which yield the inferior biological return, is therefore given by $\frac{g_{0}}{(1+n)} \frac{\left(E w-w_{0}\right)}{w_{0}}$.
} 


\subsection{Efficiency}

Inspection of our above analysis indicates that generation 0 will prefer a debt structure $\lambda^{*}$, that is a solution to (17), rather than $\lambda^{* *}$, which solves (19). ${ }^{16}$ If no government intermediation is possible, all debt structures located between $\lambda^{*}$ and $\lambda^{* *}$ are Pareto-efficient. Raising $\lambda$ beyond $\lambda^{*}$ will increase expected utility of all unborn generations at the expense of generation 0 . Starting with $\lambda^{* *}$, the same applies when $\lambda$ is lowered. Hence, we have the following proposition:

Proposition 1: If the government can only implement the debt structure that is used to roll over the initial debt, there exists a set $\left[\lambda^{*}, \lambda^{* *}\right] \subseteq[0,1]$ of efficient financing methods. This set is characterized by the conflicting interests of the current young and the yet unborn generations.

Diagrams $1 a$ and $1 b$ illustrate this trade-off:

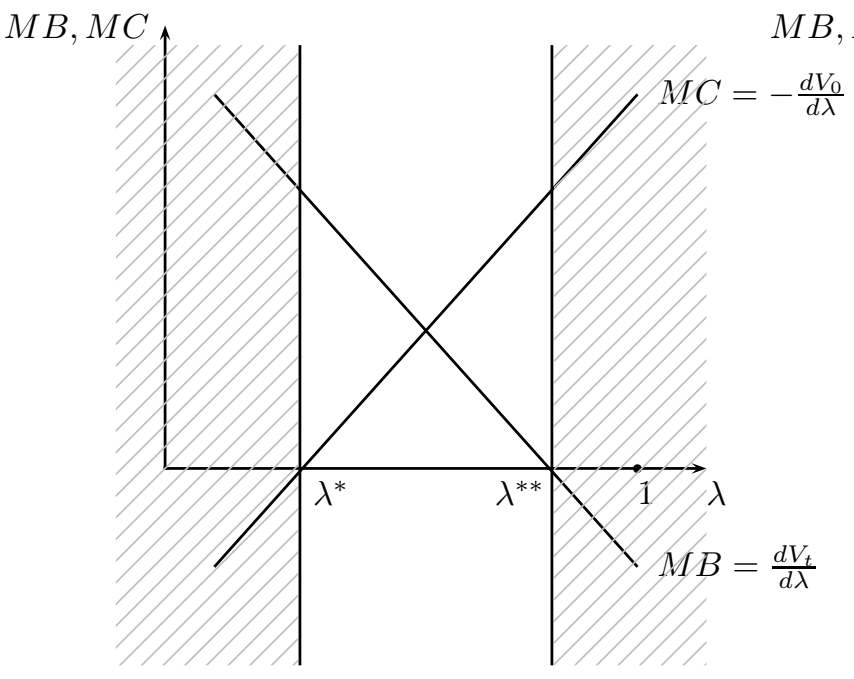

Diagram $1 a$

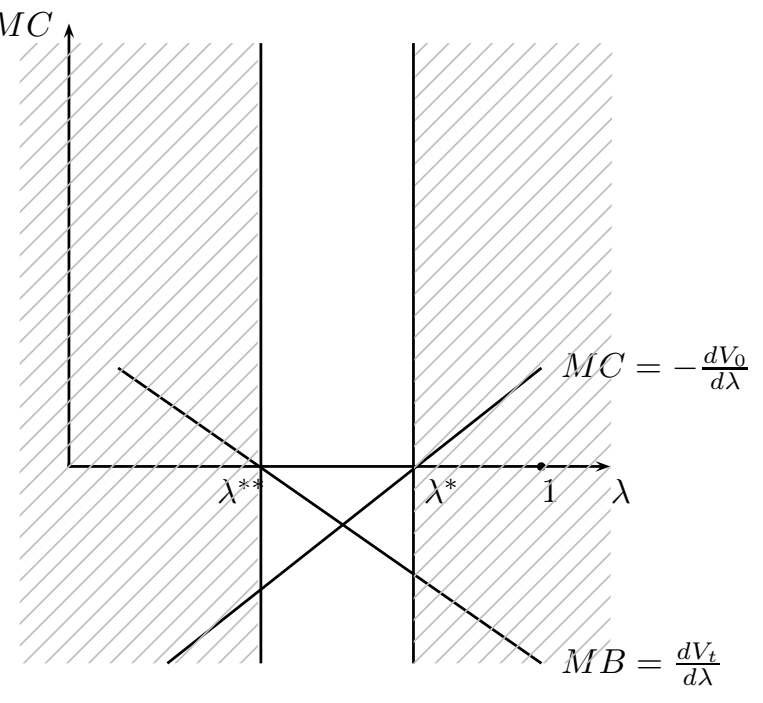

Diagram $1 b$

Diagrams $1 a$ and $1 b$ illustrate the gains and losses of generation 0 and one representative member of the yet unborn generations. All debt structures located in the dashed area are inefficient. Diagram $1 b$ depicts a situation that may occur if $E w \gg w_{0}$ and $r \gg n$.

\subsubsection{Efficiency with Government Intermediation}

Suppose now that the initial conditions are such that $\lambda=\lambda^{*}<\lambda^{* *}$. In this situation, each member of the yet unborn generations is willing to pay a premium $\pi\left(\lambda^{*}, \tilde{\lambda}\right)>0$ to reach the higher utility which is associated with some $\tilde{\lambda} \in\left(\lambda^{*}, \lambda^{* *}\right]$. Taking into

\footnotetext{
${ }^{16}$ For appropriate $\left(E w-w_{0}, r-n, \operatorname{cov}(w, R)\right), \lambda^{*}$ may actually coincide with $\lambda^{* *}$. In this case both generations prefer - though for different reasons - the same debt structure, and, except for choosing this structure, no additional government intervention is necessary. The same applies when corner solutions coincide.
} 
account the proportions between generation 0 and its successors, the government can offer each member of generation 0 resources amounting to:

$$
\alpha=\sum_{t=1}^{\infty} \pi\left(\frac{1+n}{1+r}\right)^{t}={ }_{\mid r>n} \pi\left(\frac{1+n}{r-n}\right) ; \quad \pi\left(\lambda^{*}, \tilde{\lambda}\right)=\int_{\lambda^{*}}^{\tilde{\lambda}} \frac{d V_{t}(\lambda)}{d \lambda} d \lambda .
$$

The revenue $\alpha$, which is available to compensate generation 0 , can then be raised by issuing additional bonds ${ }^{17}$ These bonds are rolled over until they are, little by little, redeemed (principal and all accrued interest) by collecting a tax revenue $\pi$ from each member of subsequent generations. The (social) cost $\pi_{0}\left(\lambda^{*}, \tilde{\lambda}\right)=\int_{\lambda^{*}}^{\tilde{\lambda}} \frac{d V_{0}(\lambda)}{d \lambda} d \lambda$ associated with $\tilde{\lambda}$ is the higher wage related risk that generation 0 has to bear. By means of such a compensation, it is now possible to recover the surpluses that are associated with a debt structure of $\lambda^{* * *}$ (equation (23) below) in a Pareto-improving manner.

Proposition 2: The intertemporal budget constraint of the government can be used to reconcile the interests of members of generation 0 and the yet unborn generations. Resources and risks can simultaneously and independently be transferred from the young to the old and vice versa. Hence, there exists only one efficient financing method $\lambda^{* * *}$, which maximizes the Marshallian surplus from intergenerational risk-sharing.

Remark 1: While the Optimum structure for debt $\lambda^{* * *}$ is unique, there are infinitely many ways to distribute the associated efficiency gains among the cohorts.

Remark 2: Proposition 2 neglects the income effects that are associated with the distribution of the efficiency gains mentioned in Remark 1. As the income effects may slightly influence the agents preferences, $\lambda^{* * *}$ may in fact depend on the particular distribution scheme.

Remark 3: If the initial debt structure is such that $\lambda>\lambda^{* * *}$, some of the efficiency gains associated with the implementation of $\lambda^{* * *}$ can be passed forward to compensate the unborn generations. In this case, generation 0 gives up resources in exchange for lower labor income risk.

Remark 4: To keep in touch with the steady state as a reference point, Proposition 2 neglects the possibility of a repeated restructuring of the debt.

As Diagram $2 a$ (below) illustrates, the particular compensation mechanism described in 22 increases utility of generation 0 only. We may as well consider a compensation scheme that allocates resources as if there existed a competitive market for $\lambda$, where every member of society can participate. The optimum structure for government debt $\lambda^{* * *}$, which maximizes market rent, is then the root of 18

$$
\frac{d V_{0}(\lambda)}{d \lambda}+\sum_{t=1}^{\infty} \frac{d V_{t}(\lambda)}{d \lambda}\left(\frac{1+n}{1+r}\right)^{t}=0 . \quad \Leftrightarrow \quad \frac{\frac{d V_{0}(\lambda)}{d \lambda}}{\frac{d V_{t}(\lambda)}{d \lambda}}=-\left(\frac{1+n}{r-n}\right) .
$$

\footnotetext{
${ }^{17}$ In principle, the government may issue debt of any maturity. For infinitely lived bonds, that pay one unit of interest per period, the government has to float a total number $b$ of bonds, where $b=\alpha r$.

${ }^{18}$ The maximization problem corresponding to condition 23 is given by: $\max _{\lambda} \int_{0}^{\lambda}\left[\frac{d V_{0}(s)}{d s}+\sum_{t=1}^{\infty}\left(\frac{1+n}{1+r}\right)^{t} \frac{d V_{t}(s)}{d s}\right] d s$, s.t. 8 , 10,11 .
} 
Note that condition (23) may also be interpreted as an intertemporal version of the Samuelson (1954) condition for the efficient provision of a public good. All future generations benefit from the public good "risk-sharing" which is embodied in the debt scheme. The costs with the provision of this public good that can be used by all subsequent generations alike has to be incurred only once by generation 0 , which has to bear additional wage-related risks. The second formulation of this first-order condition is written in terms of marginal rates of substitution of wage related risks between generation 0 and all subsequent generations. The relative price depends on the proportions between the generations and the savings technology. For $n=0$, the price is that of an infinitely lived safe bond which yields one unit of the consumption good in each period.

As with the provision of public goods, there also exist income effects (Remark 1 and 2) once different compensation schemes are implemented. Hence, the exact location (not its existence) of $\lambda^{* * *}$ actually depends on the particular compensation scheme as the associated income effects may slightly change preferences for $\lambda$, i.e. shift the marginal cost and benefit curves. For expositional convenience Diagram 2 abstracts from these shifts:

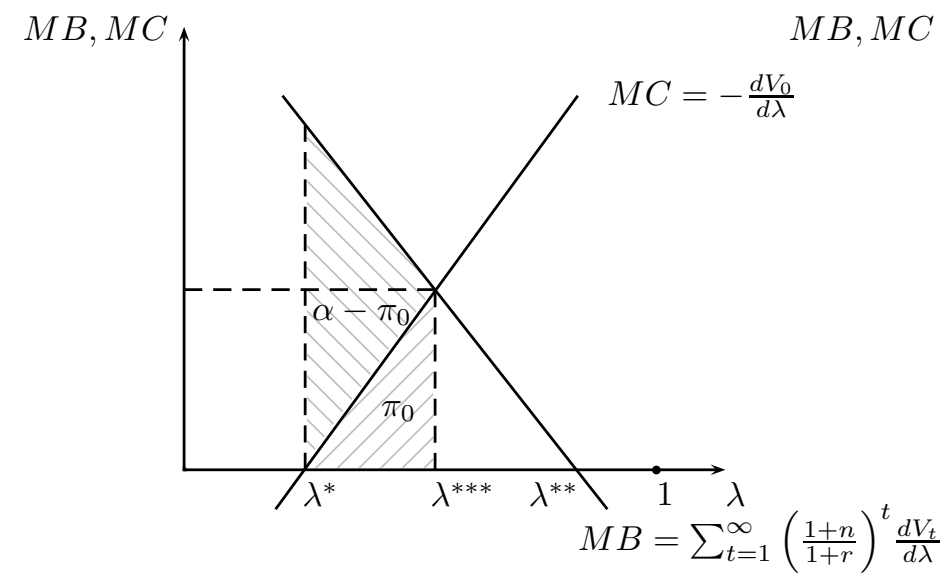

Diagram $2 a$

$$
M B=\sum_{t=1}^{\infty}\left(\frac{1+n}{1+r}\right)^{t} \frac{d V_{t}}{d \lambda}
$$

Diagram $2 a$ illustrates the compensation described in 22). In this case, all efficiency gains $\alpha-\pi_{0}$ go to generation 0 . In Diagram $2 b$, we add up (vertically) the respective, biologically and technologically adjusted, "demands" of the members of all subsequent generations. Together with the marginal costs for members of generation 0 , these localize the optimum structure for government debt, which maximizes the Marshallian surplus.

\section{Extensions}

So far attention was confined to an economy where the safe rate-of-return is constant over time. The prospects of a third debt instrument, namely a defined benefit social security system, have also been neglected. In a first step, we now show that a timevarying, safe rate-of-return does not alter the quality of the foregoing conclusions 
and that defined benefits are equivalent to safe bonds. Finally a second group of representative agents who do not invest in the stock market (risky technology) is introduced into our model. In this setting we show that both groups require different social security contribution rates, i.e., debt structures. If either is at a corner solution there is additional scope for an intragenerational reallocation of the public debt.

\subsection{Time-Varying Safe Returns}

To work out the pivotal elements, the safe rate of return was assumed to remain constant over time. However, the main results of our previous analysis carry over to an economy where $r$ is now an i.i.d. random variable. Regarding generation 0 , nothing is changed, i.e., the agents and the social planner start maximizing after $r_{1}$ is known. Except for the additional expectations regarding $r$ the long-run planning problem 190 is also little changed:

$$
\begin{array}{cl}
\max _{\lambda} V_{t}=\quad & E_{w_{t}, r_{t+1}}\left[U\left(w_{t}\left(1-\lambda \frac{g_{0}}{w_{0}(1+n)}\right)-\frac{r_{t+1}-n}{\left(1+r_{t+1}\right)} \frac{(1-\lambda) g_{0}}{(1+n)}-a_{t}-h_{t}\right)\right] \\
& +\beta E_{w_{t} w_{t+1} R_{t+1} r_{t+1}}\left[U\left(a_{t}\left(1+r_{t+1}\right)+h_{t}(1+R)+\lambda \frac{g_{0}}{w_{0}} w_{t+1}\right)\right] .
\end{array}
$$

Employing the envelope conditions $(13)$ and (14), yields:

$$
\begin{aligned}
\frac{d V_{t}}{d \lambda}= & \frac{g_{0}}{(1+n)}\left(E_{w r}\left[\frac{r_{t+1}-n}{1+r_{t+1}} U^{\prime}\left(c^{1}\right)\right] \frac{w_{0}-E[w]}{w_{0}}\right. \\
& \left.\left.-\operatorname{cov}_{w_{t} r_{t+1}}\left(U^{\prime}\left(c^{1}\right), \frac{w_{t}}{w_{0}}\right)+\beta(1+n) \operatorname{cov}_{r_{t+1} w_{t} w_{t+1} R}\left(U^{\prime}\left(c^{2}\right), \frac{w_{t+1}}{w_{0}}\right)\right]\right)=0 .
\end{aligned}
$$

Due to the nature of the treasury's tax schedule (11), the initial interest rate $r_{1}$ does not, unlike the wage rate $w_{0}$, enter into the long-run first order condition. While there are now additional expectations regarding the safe rate of return, the principal structure of the first order condition is preserved. Regarding our Pareto-improving interventions that were discussed in Section 2.5, we note that the government can still reallocate gains and losses along its budget constraint. However, each compensation scheme will now require some sort of risk-taking.

\subsection{Defined Benefits}

We will now briefly show that a defined benefit system is equivalent to an explicit debt scheme. The budget constraint of a defined benefit system, which is used to roll over a fraction $\gamma$ of the public debt, is given by:

$$
\tau_{t}^{D B} w_{t}=\frac{\gamma g_{0}}{(1+n)}, \quad p_{t}^{D B}=\gamma g_{0}
$$

Once we recall that the young agent can consume $c^{1}$, invest an amount $a$ into safe assets and an amount $h$ into risky assets, the present value budget constraint is given by:

$$
c_{t}^{1}+a_{t}+h_{t}=w_{t}\left(1-\tau_{t}^{D B}-\tau_{t}^{t}\right)+\frac{p_{t+1}^{D B}}{\left(1+r_{t+1}\right)} .
$$


Utilizing (25) and (11) where $(1-\lambda)$ is replaced by $(1-\gamma)$, the right-hand side of (26) can now be rewritten such that:

$$
c_{t}^{1}+a_{t}+h_{t}=w_{t}-\frac{g_{0}\left(r_{t+1}-n\right)}{(1+n)\left(1+r_{t+1}\right)} .
$$

Hence the structure of debt $\gamma$ is irrelevant, i.e. a defined benefit system is equivalent to a bond-financed debt scheme.

\subsection{A Working Class}

This final paragraph, considers a society that is partitioned into a group of capitalists who are endowed with a large amount of efficient labor and a group of workers with a low labor endowment. While capitalists participate in the stock-market, workers invest in the safe technology only ${ }^{19}{ }^{20}$ To simplify notation, we assume that the working class makes up two thirds of the population and each worker has only one half of the effective labor endowment of a capitalist. Hence, there are two workers for each capitalist and the group of workers earns one half of the aggregate wage income. Replacing $\frac{g_{0}}{1+n}$ in (8) and (11) by $\frac{1}{2} \frac{g_{0}}{1+n}$ and $\frac{1}{4} \frac{g_{0}}{1+n}$ for capitalists and workers respectively, yields the new tax rates. Workers will now choose safe investment according to (13). The optimal shares of debt for the working class, $\lambda_{w}^{*}, \lambda_{w}^{* *}$ are then characterized by (17) and (19), with the notable difference that $h=0 .{ }^{21}$ For

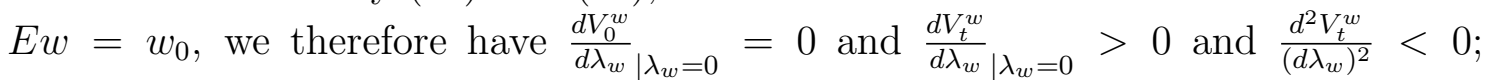
i.e. a unique globally optimal debt structure $\lambda_{w}^{* * *}$ exists if $g_{0}$ is large enough (see (B.6) in Appendix B). If per capita debt $\frac{g_{0}}{1+n} \frac{1}{4}$ is not large enough to transport a sufficient amount of wage-related risk into the retirement period, we have $\lambda_{w}^{* * *}>1$

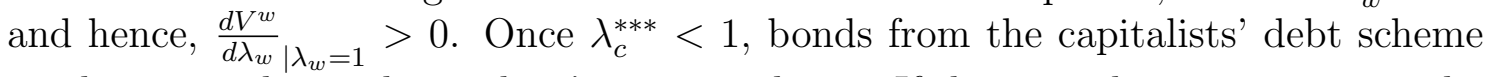
can be injected into the workers' pension scheme. If the capitalists, in turn, pay the implicit tax associated with this debt swap as a subsidy to the workers, the marginal increase in rent $R^{w}$ for workers is, recalling (21) with $\lambda_{w}=1$, given by:

$$
\frac{d R^{w}}{d g_{0}^{w}}=\frac{1}{g_{0}^{w}}\left(\frac{d V_{0}^{w}}{d \lambda_{w}}+\frac{d V_{t}^{w}}{d \lambda_{w}} \frac{1+n}{r-n}\right)>0 .
$$

Thus, while utility of the capitalists remains constant, the utility of workers has increased.

\footnotetext{
${ }^{19}$ At this point, we take the non-participation of workers in the stock-market as given; Abel (2001) endogenizes the participation decision by introducing a fixed costs that make it rational for agents with a small portfolio to abstain from the stock market. Regarding this non-participation decision, Diamond and Geanakoplos (2003) point out that roughly 50 percent of the working population in the US does not hold any stocks (this figure includes indirect holdings of stocks through pension plans).

${ }^{20}$ To focus on the intertemporal and intergenerational reallocation of risks, rather than intragenerational redistribution which can also be achieved without social security, we assume that the affiliation with the two groups of all agents is known in period $t=0$, i.e. cannot be insured against.

${ }^{21}$ Given the different labor endowment and the different exposition to the covariance risk $\left(\operatorname{cov}\left(R, w_{t+1}\right)\right)$, it is clear that it is not optimal to choose a "one-size-fits-all pension scheme". Hence we will right away allow for distinct debt structures $\lambda_{c}, \lambda_{w}$ for capitalists and workers.
} 


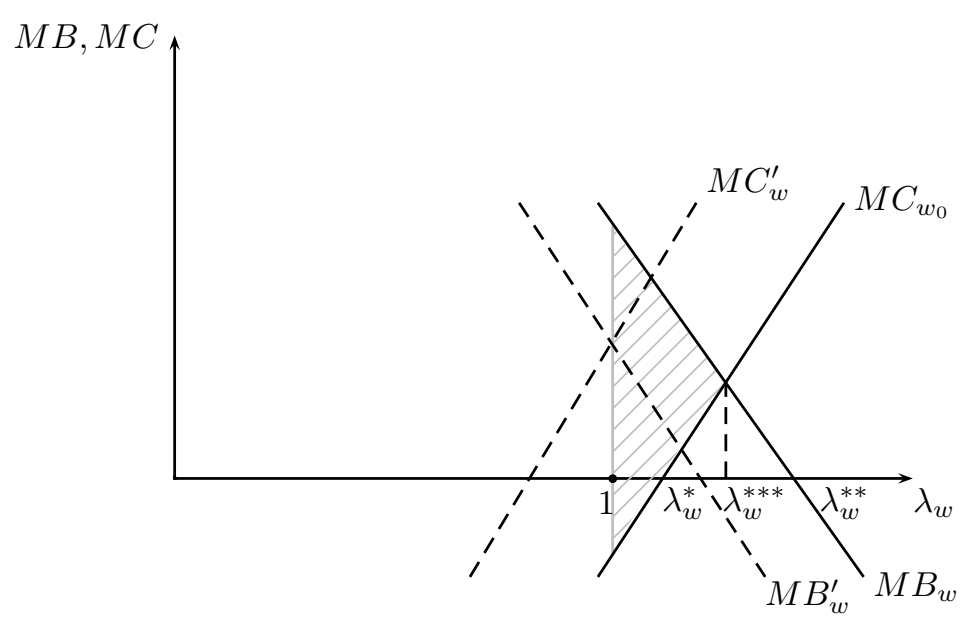

Diagram 3

The shaded area to the right of $\lambda=1$ is the welfare gain associated with an intragenerational debt swap.

To a certain extend this result illustrates the main point of our analysis. Given that we already have incurred the debt, the risk-sharing capacities of the debt are a scarce resource. Transferring some of the debt from capitalists to workers improves risk-sharing without any additional crowding out of capital.

\section{Conclusion}

If a government can issue safe bonds and claims to an unfunded social security system to service a given obligation, there exists a set of Pareto-efficient financing policies. This set is characterized by the conflicting interests of agents who are currently alive and those who are yet unborn. The current young, who have already observed their wage income, will prefer safe debt, i.e. safe retirement benefits. The unborn generations on the contrary benefit from the ex-ante diversification of their wage risk if a large portion of the initial debt is injected into social security.

The government may now act as a representative of the unborn members of society. Through its budget constraint, it can offer generation 0 a compensation that reflects the willingness to pay of all unborn agents. Such an intermediation allows to collect the benefits, which are associated with the optimum structure for government debt $\lambda^{* * *}$ in a Pareto-improving manner. If the initial conditions are such that $\lambda^{* * *}>0$, an unfunded social security system is therefore always warranted.

Unlike the deterministic economy, where all debt policies are equally desirable, the current analysis shows that the structure of government debt has distinct implications for individual welfare. If we compare our analysis to the problem of optimal capital accumulation, the following analogy is notable: While the golden rule capital intensity maximizes long-run utility it comes at the cost of lower consumption along the transition path. All capital intensities below the golden rule level are efficient and there is no compensation mechanism available. ${ }^{22}$ All government interventions

\footnotetext{
${ }^{22}$ The lack of such a compensation mechanism led to the turnpike literature; see e.g. Samuelson
} 
are either neutral or require a welfare criterion. Compared to the reallocation of aggregate risks, the situation without compensation is similar; there exists a whole set of efficient debt structures. In the present case, however, the government budget constraint can be used to reconcile the conflicting interests of the current young and those who live in the long run in a Pareto-improving manner. As a result, subject to our assumptions, there remains only one optimal structure for government debt.

\section{A Appendix}

Derivation of condition (19): Equations (13) and (14) imply an investment behavior for each realization of the wage-income $w_{t}$, namely $a_{t}=a_{t}\left(w_{t}, \lambda\right), h_{t}=h_{t}\left(w_{t}, \lambda\right)$. Hence, agents smooth consumption state by state with regard to first period wage income. At the same time, they smooth consumption in expectations when it comes to second period consumption. Taking expectations $E_{w_{t}}$ of (13) and (14) yields:

$$
\begin{aligned}
& E_{w_{t}}\left[U^{\prime}\left(c^{1}\right)\right]=\beta\left(1+r_{1}\right) E_{w_{t}}\left[E_{w_{t+1} R}\left[U^{\prime}\left(c^{2}\right)\right]\right], \\
& E_{w_{t}}\left[U^{\prime}\left(c^{1}\right)\right]=\beta E_{w_{t}}\left[E_{w_{t+1} R}\left[(1+R) U^{\prime}\left(c^{2}\right)\right]\right] .
\end{aligned}
$$

Writing out the first order condition for $\lambda^{* *}$, we obtain:

$$
\begin{aligned}
\frac{d V_{t}}{d \lambda} & =\left(E_{w_{t}}\left[-U^{\prime}\left(c^{1}\right) w_{t}+(1+n) \beta E_{w_{t+1} R}\left[w_{t+1} U^{\prime}\left(c^{2}\right)\right]\right] \frac{g_{0}}{w_{0}}\right. \\
& \left.+\frac{r-n}{(1+r)} g_{0} E_{w_{t}}\left[U^{\prime}\left(c^{1}\right)\right]\right) \frac{1}{1+n} \\
- & E_{w_{t}}\left[U^{\prime}\left(c^{1}\right)\left(\frac{d a}{d \lambda}+\frac{d h}{d \lambda}\right)-\beta E_{w_{t+1} R}\left[U^{\prime}\left(c^{2}\right)\left((1+r) \frac{d a}{d \lambda}+(1+R) \frac{d h}{d \lambda}\right)\right]\right]=0 .
\end{aligned}
$$

To rearrange the first line in A.3), equation A.1) can be utilized as $\frac{E_{w_{t}}\left[U^{\prime}\left(c^{1}\right)\right]}{1+r}=$ $\beta E_{w_{t}}\left[U^{\prime}\left(c^{2}\right)\right]$. Applying the covariance rule $(E[x y]=\operatorname{cov}(x, y)+E[x] E[y])$ to the resulting expressions, we obtain $(19)$. Noting that the derivatives $\frac{d a}{d \lambda}$ and $\frac{d h}{d \lambda}$ are functions of $w_{t}$, we can rearrange the second line, using the covariance rule, such that:

$$
\begin{aligned}
& -E_{w_{t}}\left[U^{\prime}\left(c^{1}\right)\right] E_{w_{t}}\left[\frac{d a}{d \lambda}\right]+(1+r) \beta E_{w_{t} w_{t+1} R}\left[U^{\prime}\left(c^{2}\right)\right] E_{w_{t}}\left[\frac{d a}{d \lambda}\right] \\
& -E_{w_{t}}\left[U^{\prime}\left(c^{1}\right)\right] E_{w_{t}}\left[\frac{d h}{d \lambda}\right]+\beta E_{w_{t} w_{t+1} R}\left[(1+R) U^{\prime}\left(c^{2}\right)\right] E_{w_{t}}\left[\frac{d a}{d \lambda}\right] \\
& +\operatorname{cov}_{w_{t}}\left(-U^{\prime}\left(c^{1}\right)+(1+r) \beta E_{w_{t+1} R}\left[U^{\prime}\left(c^{2}\right)\right], \frac{d a}{d \lambda}\right) \\
& +\operatorname{cov}_{w_{t}}\left(-U^{\prime}\left(c^{1}\right)+\beta E_{w_{t+1} R}\left[(1+R) U^{\prime}\left(c^{2}\right)\right], \frac{d h}{d \lambda}\right)=0 .
\end{aligned}
$$

That is, recalling (13), (14), (A.1), and (A.2), the expressions related to changes in the investment behavior vanish by the envelope theorem.

(1968) or Blanchard and Fischer (1989). The absence of such an intertemporal compensation mechanism is of course also the reason for the intertemporal efficiency of pay-go schemes that we have been referring to in footnote 1 . 


\section{B Appendix}

This appendix examines the properties of condition (19). In a first step we note that (19) characterizes a "best" debt structure, which may or may not be interior. In a next step it is shown that interior solutions will exist for appropriate parameters. Finally the conditions, which ensure that $\left.\frac{d V_{t}(\lambda)}{d \lambda}\right|_{\lambda=0}>0$ and that $\frac{d^{2} V_{t}(\lambda)}{d \lambda^{2}}<0$ are outlined.

Existence: Since short sales of bonds or social security claims were ruled out, the set of feasible debt structures $[0,1]$ is a compact subset of $\Re$. If $V_{t}(\lambda)$ is continuous and real-valued, it will therefore attain its bounds on this choice set according to the Weierstrass theorem.

Interior Solutions: If $\frac{d \operatorname{cov}\left(U^{\prime}\left(c^{1}\right), w_{t}\right)}{d \tau^{s}} \frac{d \tau^{s}}{d \lambda}$ and $\frac{d \operatorname{cov}\left(U^{\prime}\left(c^{2}\right), w_{t+1}\right)}{d \tau^{s}} \frac{d \tau^{s}}{d \lambda}$ are continuous and $\frac{d h}{d \tau^{s}}<0$, it is obvious that for sufficiently large $g_{0}$, sufficiently small $\operatorname{cov}\left(R, w_{t+1}\right)$, and $E_{w}[w]=w_{0}$ or $r=n$, we have:

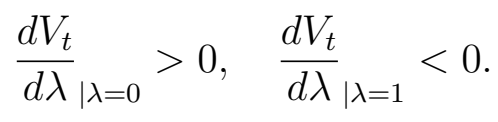

In this case, there exists one interior global optimum $\lambda^{* *}$ and there may exist several local optima.

Unique Optimum: To interpret condition (19) in more detail, we will first show that $\operatorname{cov}\left(U^{\prime}\left(c^{1}\right), w_{t}\right)<0$ and give a condition for $\operatorname{cov}\left(U^{\prime}\left(c^{2}\right), w_{t+1}\right) \gtreqless 0$ :

$$
\begin{aligned}
\operatorname{cov}\left(c^{1}, w_{t}\right) & =\quad \operatorname{cov}\left(w_{t}\left(1-\tau^{s}\right)-\frac{r-n}{1+r} \frac{g_{0}}{1+n}(1-\lambda)-s\left(w_{t}, \tau^{s}\right), w_{t}\right) \\
& =\operatorname{cov}\left(\left(1-\tau^{s}\right) w_{t}-s\left(w_{t}, \tau^{s}\right), w_{t}\right)>0,
\end{aligned}
$$

where the $\operatorname{sign} \operatorname{cov}\left(c^{1}, w_{t}\right)>0$ is due to the normality of $c^{1}$; i.e. $\frac{\partial\left(\left(1-\tau^{s}\right) w_{t}-s\left(w_{t}, \tau^{s}\right)\right)}{\partial w_{t}}>$ 0 . Hence, since $U^{\prime \prime}()<0, \operatorname{cov}\left(U^{\prime}\left(c^{1}\right), w_{t}\right)<0$. For $\operatorname{cov}\left(U^{\prime}\left(c^{2}\right), w_{t+1}\right)$ we have:

$$
\begin{aligned}
\operatorname{cov}\left(c^{2}, w_{t+1}\right) & =\quad \operatorname{cov}\left((1+r) a+(1+R) h+\tau^{s}(1+n) w_{t+1}, w_{t+1}\right) \\
& =h \operatorname{cov}\left(R, w_{t+1}\right)+\tau^{s}(1+n) \sigma_{w}^{2} \gtreqless 0 ; \quad \tau^{s}=\lambda \frac{g_{0}}{(1+n) w_{0}} .
\end{aligned}
$$

Hence, depending on the amount of risky assets $h, \operatorname{cov}(w, R) \gtreqless 0$ and the amount of debt that is injected in the pension system, we may have $\operatorname{cov}\left(U^{\prime}\left(c^{2}\right), w_{t+1}\right) \gtreqless 0$. Together with the ambiguous sign of $\frac{(n-r)\left(E w-w_{0}\right)}{w_{0}(1+r)}$, we may or may not have $\left.\frac{d V_{t}}{d \lambda}\right|_{\lambda=0}>$ 0 .

Sufficient Condition: To allow for a global optimum, it is a sufficient condition, that $\frac{d V_{t}}{d \lambda}$ is downward-sloping in $\lambda$ :

$$
\begin{aligned}
& \frac{d^{2} V_{t}}{(d \lambda)^{2}}=\frac{g_{0}}{1+n}\left(\frac{n-r}{1+r} \frac{E[w]-w_{0}}{w_{0}} \frac{d E\left[U^{\prime}\left(c^{1}\right)\right]}{d \lambda}\right. \\
& \left.-\frac{d \operatorname{cov}_{w_{t}}\left(U^{\prime}\left(c^{1}\right), \frac{w_{t}}{w_{0}}\right)}{d \lambda}+\beta(1+n) \frac{d \operatorname{cov}_{w_{t+1} R}\left(U^{\prime}\left(c^{2}\right), \frac{w_{t+1}}{w_{0}}\right)}{d \lambda}\right)<0 .
\end{aligned}
$$


A first inspection of (B.5) indicates that for $E w=w_{0}$ and/or $r=n$, we expect $\frac{d \operatorname{cov}\left(U^{\prime}\left(c^{1}\right), w_{t}\right)}{d \lambda}>0, \frac{d \operatorname{cov}\left(U^{\prime}\left(c^{2}\right), w_{t+1}\right)}{d \lambda}<0$ and thus $\frac{d^{2} V_{t}}{d \lambda^{2}}<0.23$ With respect to $\frac{d \operatorname{cov}\left(U^{\prime}\left(c^{1}\right), w_{t}\right)}{d \lambda}$ we have:

$$
\begin{aligned}
\frac{d \operatorname{cov}_{w_{t}}\left(U^{\prime}\left(c^{1}\right), w_{t}\right)}{d \lambda} & =\operatorname{cov}_{w_{t}}\left(U^{\prime \prime}\left(c^{1}\right),\left(-w-\frac{\partial s}{\partial \tau^{s}}\right) \frac{d \tau^{s}}{d \lambda}\right) \\
& \approx E_{w_{t}}\left[U^{\prime \prime}\left(c^{1}\right)\right] \operatorname{cov}_{w_{t}}\left(-w-\frac{\partial s}{\partial \tau^{s}}, w\right) \frac{d \tau^{s}}{d \lambda}>0
\end{aligned}
$$

where $\frac{\partial\left(\frac{\partial s}{\partial w}\right)}{\partial \tau^{s}}=\frac{\partial\left(\frac{\partial s}{\partial \tau^{s}}\right)}{\partial w}>-1$, due to the normality of first period consumption. Moreover, B.6 holds with strict equality if $U^{\prime \prime \prime}\left(c^{1}\right)=0$. Finally we have:

$$
\frac{d \operatorname{cov}\left(U^{\prime}\left(c^{2}\right), w_{t+1}\right)}{d \lambda}=E_{w R}\left[U^{\prime \prime}\left(c^{2}\right)\right]\left(\frac{\partial h}{\partial \tau^{s}} \operatorname{cov}\left(R, w_{t+1}\right)+(1+n) \sigma_{w}^{2}\right) \frac{d \tau^{s}}{d \lambda} \gtreqless(, \mathrm{B} .7)
$$

where (B.7) is negative if $\frac{\partial h}{\partial \tau} \operatorname{cov}\left(R, w_{t+1}\right)+(1+n) \sigma_{w}^{2}>0$. If $\operatorname{cov}\left(R, w_{t+1}\right)$ is large and positive and the share of savings invested in the risky technology is also very large, the crowding-out effect of additional pension claims may in principle overcompensate the direct effect of the exposition to additional wage-related risks once $\lambda$ is increased.

\section{References}

Aaron, H., 1966. The social insurance paradox. Canadian Journal of Economics and Political Science 32 (3), 371-374.

Abel, A. B., 2001. The effects of investing social security funds in the stock market when fixed costs prevent some households from holding stocks. American Economic Review 91 (1), 128-148.

Ball, L., Mankiw, G., 2001. Intergenerational risk sharing in the spirit of Arrow, Debreu, and Rawls, with applications to social security design. NBER Working Paper (8270), 1-40.

Ball, L., Mankiw, G., 2007. Intergenerational risk sharing in the spirit of Arrow, Debreu, and Rawls, with applications to social security design. Journal of Political Economy 115 (4), 523-547.

Belan, P., Pestieau, P., 1999. Privatizing social security: A critical assessment. The Geneva Papers on Risk and Insurance 24 (1), 114-130.

Blanchard, O. J., Fischer, S., 1989. Lectures on Macroeconomics. Cambridge, MA: MIT Press.

\footnotetext{
${ }^{23}$ Regarding the first element, which is inherently ambiguous, we note that for $U^{\prime \prime \prime}\left(c^{1}\right)>0$, $\frac{d E\left[U\left(c^{1}\right)\right]}{d \lambda}$ is most likely negative, as the variance of first period consumption is decreasing in $\lambda$.
} 
Bohn, H., 1998. Risk sharing in a stochastic overlapping generations economy. Economics Working Paper Series (1076), 1-44.

Bohn, H., 2003. Intergenerational risk sharing and fiscal policy. Working paper, University of California at Santa Barbara, 1-35.

Breyer, F., 1989. On the intergenerational pareto efficiency of pay-as-you-go financed pension systems. Journal of Institutional and Theoretical Economics (145), 643658.

Cass, D., Yaari, M. E., 1966. A re-examination of the pure consumption loans model. Journal of Political Economy 74 (4), 353-367.

De La Croix, D., Michel, P., 2002. A Theory of Economic Growth. Cambridge: Cambridge Univ. Press.

Diamond, P. A., 1965. National debt in a neoclassical growth model. American Economic Review 55 (5), 1126-1150.

Diamond, P. A., 1977. A framework for social security analysis. Journal of Public Economics 8 (3), 275-298.

Diamond, P. A., 1996. Proposals to restructure social security. The Journal of Economic Perspectives 10 (3), 67-88.

Diamond, P. A., 2000. Towards an optimal social security design. CeRP Working Paper (4), 4-17.

Diamond, P. A., Geanakoplos, J., 2003. Social security investment in equities. American Economic Review 93 (4), 1047-1074.

Enders, W., Lapan, H. E., 1982. Social security taxation and intergenerational risk sharing. International Economic Review 23 (3), 647-658.

Fenge, R., 1995. Pareto-efficiency of the pay-as-you-go pension system with intragenerational fairness. Finanzarchiv 52 (3), 357-363.

Fischer, S., 1983. Welfare aspects of government issue of indexed bonds. In: Inflation, Debt and Indexation. ed. R. Dornbusch and M. Simonsen, MIT Press, pp. 223246.

Friedman, M., 1999. Speaking the truth about social security reform. Cato Institute Briefing Papers (46), 1-3.

Gale, D., 1990. The efficient design of public debt. In: Public debt management: theory and history. ed. R. Dornbusch and M. Draghi, Camebridge University Press, pp. 14-41.

Gordon, R. H., Varian, H. R., 1988. Intergenerational risk sharing. Journal of Public Economics 37 (1), 185-202. 
Gottardi, P., Kubler, F., 2008. Social security and risk sharing. Working Paper, $1-40$.

Green, J. R., 1977. Mitigating demographic risk through social insurance. NBER Working Paper (215), 1-32.

Krüger, D., Kubler, F., 2005. Pareto improving social security reform when financial markets are incomplete. American Economic Review 96 (3), 737-755.

Lerner, A. P., 1959. Consumption-loan interest and money. Journal of Political Economy $67(5), 512-518$.

Ludwig, A., Reiter, M., 2009. Sharing demographic risk - who is afraid of the baby bust. Working Paper Köln University, 1-47.

Merton, R., 1983. On the role of social security as a means for efficient risk sharing in an economy where human capital is not tradable. In: Financial Aspects of the United States Pension System. ed. Z. Bodie and J. Shoven, University of Chicago Press, Chicago, pp. 259-290.

Samuelson, P. A., 1954. The theory of public expenditure. Review of Economics and Statistics 36 (4), 386-389.

Samuelson, P. A., 1958. An exact consumption-loan model of interest with or without the social contrivance of money. Journal of Political Economy 66 (6), 467-482.

Samuelson, P. A., 1959. Consumption-loan interest and money: Reply. Journal of Political Economy 67 (5), 518-522.

Samuelson, P. A., 1968. The two-part golden rule deduced as the asymptotic turnpike of catenary motions. Western Economic Journal (VI , March, 1968), 85-89.

Samuelson, P. A., 1975. Optimum social security in a life-cycle growth model. International Economic Review 16 (3), 539-544.

Shiller, R., 1999. Social security and institutions for intergenerational, intragenerational and international risk sharing. Carnegie-Rochester Conference Series on Public Policy 50, 165-204.

Sinn, H. W., 2000. Why a funded pension system is useful and why it is not useful. International Tax and Public Finance 7 (4-5), 389-410. 


\section{Discussion Paper Series}

Mannheim Research Institute for the Economics of Aging, Universität Mannheim

To order copies, please direct your request to the author of the title in question.

\begin{tabular}{|c|c|c|c|}
\hline Nr. & Autoren & Titel & Jahr \\
\hline $182-09$ & $\begin{array}{l}\text { Steffen Reinhold, } \\
\text { Kevin Thom }\end{array}$ & $\begin{array}{l}\text { Temporary Migration and Skill Upgrading: } \\
\text { Evidence from Mexican Migrants }\end{array}$ & 09 \\
\hline 183-09 & $\begin{array}{l}\text { Hendrik Jürges, } \\
\text { Eberhard Kruk, } \\
\text { Steffen Reinhold }\end{array}$ & $\begin{array}{l}\text { The effect of compulsory schooling on health - } \\
\text { evidence from biomarkers }\end{array}$ & 09 \\
\hline 184-09 & $\begin{array}{l}\text { Nicola Fuchs- } \\
\text { Schündeln, Dirk } \\
\text { Krüger, Mathias } \\
\text { Sommer }\end{array}$ & $\begin{array}{l}\text { Inequality Trends for Germany in the Last Two } \\
\text { Decades: A Tale of Two Countries }\end{array}$ & 09 \\
\hline $185-09$ & $\begin{array}{l}\text { Francesco Cinnirella, } \\
\text { Joachim Winter }\end{array}$ & $\begin{array}{l}\text { Size Matters! Body Height and Labor Market } \\
\text { Discrimination: A Cross-European Analysis }\end{array}$ & 09 \\
\hline $186-09$ & $\begin{array}{l}\text { Hendrik Jürges, } \\
\text { Steffen Reinhold, } \\
\text { Martin Salm }\end{array}$ & $\begin{array}{l}\text { Does Schooling Affect Health Behavior? } \\
\text { Evidence from Educational Expansion in } \\
\text { Western Germany }\end{array}$ & 09 \\
\hline $187-09$ & Michael Ziegelmeyer & $\begin{array}{l}\text { Das Altersvorsorge-Verhalten von } \\
\text { Selbständigen - eine Analyse auf Basis der } \\
\text { SAVE-Daten }\end{array}$ & 09 \\
\hline 188-09 & $\begin{array}{l}\text { Beatrice Scheubel, } \\
\text { Daniel Schunk, } \\
\text { Joachim Winter }\end{array}$ & $\begin{array}{l}\text { Don't raise the retirement age! An experiment } \\
\text { on opposition to pension reforms and East- } \\
\text { West differences in Germany }\end{array}$ & 09 \\
\hline $189-09$ & Martin Gasche & $\begin{array}{l}\text { Die sozialversicherungspflichtig Beschäftigten } \\
\text { im deutschen Sozialversicherungssystem: } \\
\text { Eigenschaften, Beitragsleistungen und } \\
\text { Leistungsbezug }\end{array}$ & 09 \\
\hline $190-09$ & Martin Gasche & $\begin{array}{l}\text { Implizite Besteuerung im deutschen } \\
\text { Sozialversicherungssystem }\end{array}$ & 09 \\
\hline 191-09 & $\begin{array}{l}\text { Alexander Ludwig, } \\
\text { Alexander Zimper }\end{array}$ & $\begin{array}{l}\text { Biased Bayesian learning and the risk-free } \\
\text { rate puzzle }\end{array}$ & 09 \\
\hline 192-09 & $\begin{array}{l}\text { Tabea Bucher- } \\
\text { Koenen }\end{array}$ & $\begin{array}{l}\text { Financial Literacy and Private Old-age } \\
\text { Provision in Germany - Evidence from SAVE } \\
2008 \text { - }\end{array}$ & 09 \\
\hline 193-09 & $\begin{array}{l}\text { Axel Börsch-Supan, } \\
\text { Martin Gasche, } \\
\text { Michael Ziegelmeyer }\end{array}$ & $\begin{array}{l}\text { Auswirkungen der Finanzkrise auf die private } \\
\text { Altersvorsorge }\end{array}$ & 09 \\
\hline 194-09 & Wolfgang Kuhle & The Optimum Structure for Government Debt & 09 \\
\hline
\end{tabular}

